\title{
Libros y primer Humanismo en Salamanca. Inventarios y ámbitos del patrimonio librario del Colegio Mayor de San Bartolomé de la Universidad de Salamanca entre 1433 y 1440
}

JIMÉNEZ LÓPEZ, Jorge

Ediciones Universidad de Salamanca, Salamanca, 2020

ISBN: 978-84-1311-329-6

Jorge Jiménez López presenta Libros y primer Humanismo en Salamanca. Inventarios y ámbitos del patrimonio librario del Colegio Mayor de San Bartolomé de la Universidad de Salamanca entre 1433 y 1440, que resulta de un ambicioso proyecto de investigación centrado en la relación del arzobispo Diego de Anaya con sus libros y el Colegio Mayor de San Bartolomé. Como consecuencia, esta monografía se introduce como punto de referencia básico para el conocimiento de la colección libraria y los distintos espacios del libro en la institución universitaria.

Buena parte del volumen nace de la tesis doctoral defendida en la Universidad de Salamanca en el año 2019, titulada Cultura visual y libraria del arzobispo Diego de Anaya del Colegio Mayor de San Bartolomé entre 1433 y 1440, bajo la dirección de la catedrática Lucía Lahoz. El autor fundamenta su análisis en tres bases esenciales: el Ms. Espagnol 524 de la Biblioteca Nacional de Francia, la documentación relativa al arzobispo, y los manuscritos de la Biblioteca General Histórica del propio estudio.

La publicación, editada por Ediciones Universidad de Salamanca y prologada por Lahoz, se estructura en cinco apartados principales. Además de la introducción y consideraciones finales, se incluyen los índices onomásticos, de los títulos, manuscritos identificados y una relación de aquellos que se encuentran iluminados.

Los primeros tres capítulos plantean un nutrido panorama centrado en las bibliotecas medievales en las coronas de Castilla y Aragón y, concretamente, de las universitarias. Este contexto se completa con las cuestiones metodológicas e historiográficas fundamentales basadas en el estudio

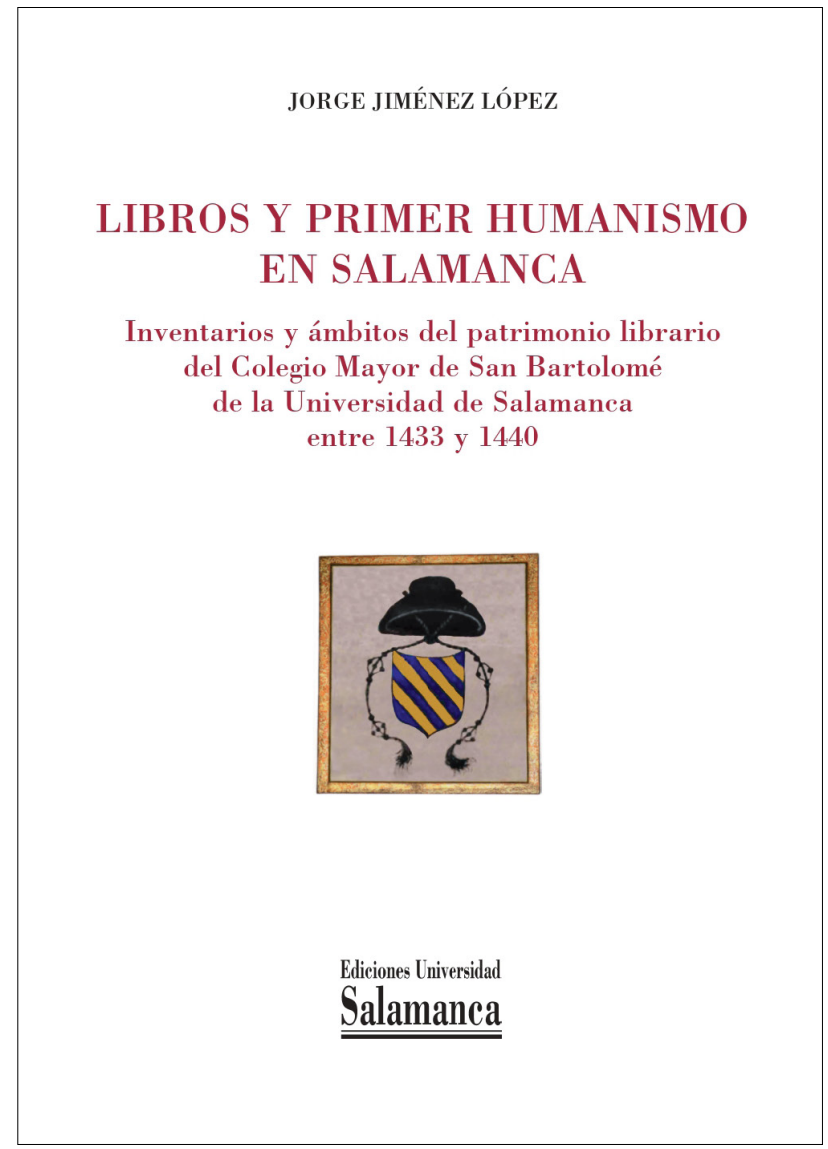

de los inventarios de libros como medio de reconstrucción de colecciones. Los apartados resultan de gran interés para la historia de las universidades hispanas, incidiendo también en los aciertos y desaciertos por parte de la histo-

Cómo citar este artículo: ROJAS BUSTAMANTE, Juan Pablo, "JIMÉNEZ LÓPEZ, Jorge: Libros y primer Humanismo en Salamanca. Inventarios y ámbitos del patrimonio librario del Colegio Mayor de San Bartolomé de la Universidad de Salamanca entre 1433 y 1440, Boletín de Arte-UMA, n. 42 , Departamento de Historia del Arte, Universidad de Málaga, 2021, pp. 329-330, ISSN: 0211-8483, e-ISSN: 2695-415X, DOI: http://dx.doi.org/10.24310/BoLArte.2021.vi42.11943 
riografía. El autor no solamente ofrece un análisis actualizado del objeto de estudio, sino que expone la metodología al abordar el patrimonio bibliográfico, facilitando su aplicación en otros centros.

El siguiente capítulo aborda la edición del Ms. Espagnol 524 de la Bibliothèque National de France, fuente principal para conocer los libros de la Casa y de su fundador. De su revisión, el investigador recupera aquella información que no se había tenido en cuenta, viniendo a completar un importante vacío historiográfico del fondo de libros pertenecientes a Anaya. Se trata sin duda del bloque temático central de la investigación, en el que se incluyen los nueve inventarios de la librería. No se entiende cómo hasta ahora, la historiografía se había limitado a manejar la información elaborada en el siglo XVIII, con un enfoque propio de aquella época y con un solo inventario.

Tras un minucioso análisis, el profesor Jiménez subraya la relevancia del Ms. 524 como testimonio principal para el estudio de la historia del Colegio, pero también para conocer el contenido de una biblioteca en España durante la Baja Edad Media. A lo anterior se suma la importancia de los inventarios de los libros que figuran en dicho manuscrito, que contaban con una primera transcripción desarrollada por Juan Pérez Millán en 1929 que hasta el momento había permanecido intacta.

Una vez transcrito el material completo, el autor identifica y ordena los títulos, lo que le permite determinar el contenido del patrimonio librario del Colegio entre 1433 y 1440. Deduce que estaba conformado por los libros de la librería colegial, los de Diego de Anaya, los depositados en las Arcas y los que se custodiaban en la sacristía. La rigurosa edición incluida en la reseñada publicación presenta unas conclusiones clarificadoras de los contenidos, siguiendo los parámetros de los repertorios de inventarios de bibliotecas universitarias empleados en los corpus europeos.

De la organización de las series agrupadas por unidades bibliográficas, Jiménez ha detectado la procedencia de cada lista, que articula mediante códigos numéricos que facilitan la ubicación de cada volumen, consistentes en los dos últimos dígitos del año seguidos de la posición dentro de cada serie. Respecto de la identificación de volúmenes, ha cotejado los títulos conservados en la Biblioteca General Histórica de la Universidad de Salamanca que figuran como procedentes del Colegio Mayor de San Bartolomé, con sus respectivas referencias de concordancia.

El contenido revelado da a conocer el sustrato intelectual asentado durante el primer Humanismo en Salamanca, desmontando la imagen conocida de Anaya como bibliófilo, puesto que fueron los colegiales de San Bartolomé quienes configuraron la biblioteca comunitaria según sus propios intereses, como se evidencia con las firmas de los inventarios por personalidades como Pedro de Osma, Alonso de Paradinas, Alfonso de la Torre o Alonso Fernández de Madrigal.

Asimismo, gracias a esta fuente, el profesor de Historia del Arte de la Universidad de Zaragoza consigue definir los espacios destinados al libro en el Colegio Mayor: la Librería comunitaria, la colección personal de Anaya, y los de la capilla, que conforman el siguiente capítulo temático. Se completa el epígrafe con la visualización de los principales puntos teológicos y de debate religioso del periodo analizado.

Con este volumen, Ediciones Universidad de Salamanca incluye dentro del repertorio historiográfico fundamental de la institución académica el relevante estudio de Jiménez López. Además de funcionar como manual metodológico para el análisis del patrimonio librario, proporciona un actualizado examen de las dinámicas universitarias del siglo XV, de la colección de libros del Colegio Mayor de San Bartolomé y de sus respectivos espacios dentro de la topografía colegial. En definitiva, la publicación sistemática y completa de los inventarios del Ms. Espagnol 524 abre un fecundo campo de investigación interdisciplinar competente dentro de los altos estándares académicos a nivel nacional e internacional.
Juan Pablo Rojas Bustamante

Universidad de Salamanca 